\title{
A Reliability Accelerated Test of High-speed Punch Based on Failure Analysis
}

\author{
Lan Chen ${ }^{2}$, Xinzhou Zhang ${ }^{1, a}$, Shuyuan Gan ${ }^{1}$ and Yuan Wang ${ }^{1}$ \\ ${ }^{1}$ School of Mechanical Engineering, Jiangsu University, Zhenjiang, 212013, China \\ 2 Jingjiang College, Jiangsu University, Zhenjiang, 212013, China
}

\begin{abstract}
By analyzing the maintainability data of a certain high-speed punch, its main fault modes, such as oil/gas parts damage, parts damage and leakages, were identified. According to the fault signal measurability and the accelerated failure mechanism, the content and scheme of a reliability accelerated test (RAT) were planned specifically, which was partly verified by some tests on a high-speed punch. This paper provides a basis for the RAT of high-speed punch.
\end{abstract}

\section{Introduction}

High-speed punch is an efficient, high-precision and high-automation punching machine. The typical use is in manufacturing of huge quantities products and it has been widely used in aeronautics and astronautics, automobile, traffic and transportation, metallurgical chemical industries and so on.

Reliability accelerated test (RAT) technology, which gets more reliability information with less work, is widely used to stimulate the potential defects and improve the reliabilities of products by failure analysis [1]. However, the domestic application of the RAT technology is not so widely as it used aboard because of the limit of test technology and equipment [2]. Nelson [3] described a model and methods for analyzing agedegradation data on product performance and provided estimates of the distribution of time for product performance to degrade to a specified value while under a specified stress. Oliveira [4] analyzed some estimation methods, such as analytical, the numerical or the approximated, which can be used to obtain the time-tofailure distribution and presented an example of the application and analysis of degradation tests. Chinnam [5] demonstrated the feasibility of such an approach using 'general' polynomial regression models for degradation signal modeling. Wang [6] gave some suggestions to reduce early failures for machining center. Zhang [7] provided an optimum distribution model which can be determined as Weibull distribution, providing a theoretical basis for the failure analysis and prediction, and reliability enhancement of the numerical control machine tools. Adamyan [8] represented a methodology that can be used for identifying the failure sequences and assessing the probability of their occurrence in a manufacturing system. Tseng [9] made an optimal stepstress accelerated degradation test plan for gamma degradation processes. Wang [10] discussed the reliability of the vibration control system with uncertain parameters. Zhang [11] proposed reliability enhancement testing plan based on the analysis of the failure mechanism of $\mathrm{NC}$ rotary table.

As stated previously, there is few study on application of the RAT technology in high-speed punch. In this paper, the failure analysis of high-speed punch is analyzed, and then the content and scheme of RAT is proposed and carried out.

\section{Failure analysis of high-speed punch}

\subsection{Failure analysis}

High-speed punch is a complex and high automatic system, which is composed by many parts and accessories, and the malfunction of the parts is multifarious [12]. In order to make scientific accurate analysis and calculation, find out the weak link and provide the safeguard, it is divided into nine subsystems, such as Numerical Control System(NC), Main Transmission System(T), Electric System(E), Lubrication system(L), Balance System(B), Detecting System(D), Feed System(F), Pneumatic System(P) and Other System(R). Based on the failure data of highspeed punch, the failure positions statistics is shown in Table 1 and the histogram is shown in Fig. 1.

From the Table 1 and Fig. 1 in can see, in the malfunctions of high-speed punch, the Main Transmission System failures (including more failures of the clutch) occur mostly, about $23.5 \%$ of the total ones. The Electric System failures, including the main failure such as wiring fault, components damage and so on, account for $22.9 \%$ of the total malfunction.

\footnotetext{
a Corresponding author: zhangxinzhou1984@126.com
} 
Table 1. Frequency of failure positions.

\begin{tabular}{|c|c|c|c|}
\hline Code & Failure positions & Times & Frequency \\
\hline T & Main Transmission System & 113 & 0.235 \\
\hline E & Electric System & 110 & 0.229 \\
\hline P & Pneumatic System & 87 & 0.181 \\
\hline L & Lubrication system & 73 & 0.152 \\
\hline D & Detecting System & 46 & 0.096 \\
\hline R & Other System & 29 & 0.060 \\
\hline B & Balance System & 17 & 0.035 \\
\hline F & Feed System & 5 & 0.010 \\
\hline NC & Numerical Control System & 1 & 0.002 \\
\hline
\end{tabular}

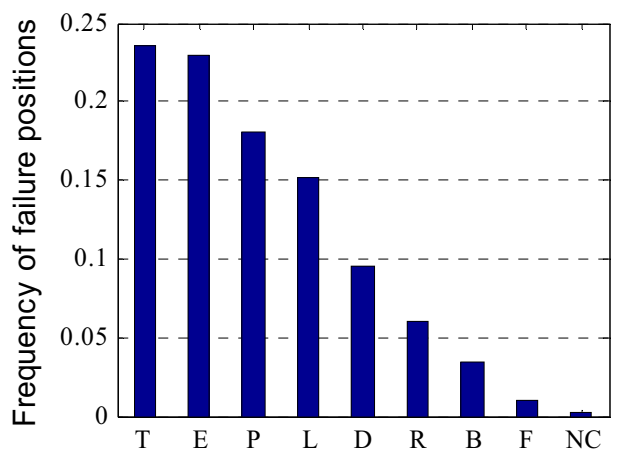

Figure 1. Histogram of failure positions.

Taken together, the Main Transmission System, the Electric System, the Pneumatic System and the Lubrication system are more positions of occurring failures in the high-speed punch and the failure of the four subsystems is about $79.7 \%$ of the total malfunction.

\subsection{Failure mechanisms analysis}

The main failure reason of the oil/gas leakage is because of the failure of airproof system. The common airproof system is usually composed by the bolt-flange-gasket connection system or the airproof ring. The main failure form of the bolt-flange-gasket connection system are the intensity failure caused by bolt failure and the gasket failure, and the airproof failure caused by leakage. The failure of airproof ring is mainly due to the deformation and abrasion of the airproof ring which causes the leakage.

The electrical line malfunction is mainly caused by the disconnection of the line and the open circuit, short circuit and undesirable contact of the cable. The main reasons of the malfunctions are that the circuit layout is not so optimization and the circuit installment quality is not so high.

\subsection{Failure measurability analysis}

Based on all kinds of failures of high-speed punch, analysis of failure measurability is shown in Table 2. According to the measurability analysis one can see that, some failure modes of the high-speed punch can be detected directly or indirectly, while some others cannot. But it is still possible to predict the occurrences of those non-detectable failures by monitoring some relative parameters. For depth analysis of the failure and performance degradation mechanism of the high-speed punch, reliability testing system need to be designed based on the measurability analysis above and other related theories. Through the analysis of experimental data, its failure and performance degradation mechanisms can be obtained.

Table 2. Analysis of failure measurability.

\begin{tabular}{|c|c|c|}
\hline Failure Mode & $\begin{array}{c}\text { Failure } \\
\text { phenomenon }\end{array}$ & $\begin{array}{c}\text { Analysis of } \\
\text { measurability }\end{array}$ \\
\hline \multirow{3}{*}{$\begin{array}{l}\text { Oil/gas } \\
\text { components } \\
\text { damage }\end{array}$} & Oil/gas tube break & \multirow{3}{*}{$\begin{array}{l}\text { Unmeasured directly, } \\
\text { can be monitored } \\
\text { indirectly by oil/gas } \\
\text { pressure, flow and so } \\
\text { on. }\end{array}$} \\
\hline & $\begin{array}{l}\text { Oil/gas pump } \\
\text { break }\end{array}$ & \\
\hline & $\begin{array}{l}\text { Oil/gas valve } \\
\text { break }\end{array}$ & \\
\hline \multirow{3}{*}{$\begin{array}{l}\text { Components } \\
\text { damage }\end{array}$} & Fastener break & Hard to measure \\
\hline & $\begin{array}{l}\text { Locking gasket } \\
\text { break }\end{array}$ & Measured by press load \\
\hline & Belting fracture & $\begin{array}{c}\text { Measured by } \\
\text { transmission torque }\end{array}$ \\
\hline Oil/gas & Seal break & $\begin{array}{c}\text { Measured indirectly by } \\
\text { pressure }\end{array}$ \\
\hline \multirow{2}{*}{$\begin{array}{l}\text { Electrical } \\
\text { components } \\
\text { damage }\end{array}$} & Transformer break & $\begin{array}{l}\text { Measured indirectly by } \\
\text { voltage, electric current } \\
\text { and so on. }\end{array}$ \\
\hline & $\begin{array}{c}\text { Control switch } \\
\text { break }\end{array}$ & Hard to measure \\
\hline $\begin{array}{c}\text { Oil/gas } \\
\text { blocking }\end{array}$ & Oil/gas blocking & $\begin{array}{l}\text { Measured by } \\
\text { cleanliness }\end{array}$ \\
\hline $\begin{array}{c}\text { Big/abnormal } \\
\text { noise of } \\
\text { machine }\end{array}$ & Big noise & Measured by noise \\
\hline $\begin{array}{l}\text { Inadequate } \\
\text { lubrication }\end{array}$ & $\begin{array}{l}\text { Inadequate } \\
\text { lubrication }\end{array}$ & $\begin{array}{c}\text { Measured by } \\
\text { lubrication pressure }\end{array}$ \\
\hline
\end{tabular}

\section{Reliability accelerated degradation test of high-speed punch}

\subsection{Accelerated analysis of failure mechanisms}

The accelerated test can be used to stimulate some specific features within a relatively short time by an appropriate higher stress, and usually the same features will come out spontaneously over a long time in normal operation. It is necessary to analyze whether the accelerated test can be used to research the failure process of high-speed punch. The judgment principles are as follow [13]: 1) The consistency of failure mechanisms: The failure mechanisms remain unchanged under different stress levels and it can be guaranteed by experimental design. 2) The regularity of failure process: There is a certain relationship between the product life and stress, namely the existence of accelerated model. 3) The identity of failure distribution: The product life under different stress levels follows the same distribution.

These conductions are essential for experimental design and analysis in accelerated test. According to the analysis of the bottom dead center (BDC) data of the high-speed punch, one can know that the repetitive dynamic accuracy of the BDC reduces with the increase of stamping speed, which is shown in Fig. 2. Therefore, the acceleration is feasible during the accuracy degradation of the bottom dead center. As the acceleration will not change the failure mechanisms, the performance degradation of the BDC and other parts can 
be accelerated by increasing the punch speed. Consequently, the purpose of RAT for high-speed punch can be achieved by scientific experimental design without change of failure mechanisms.

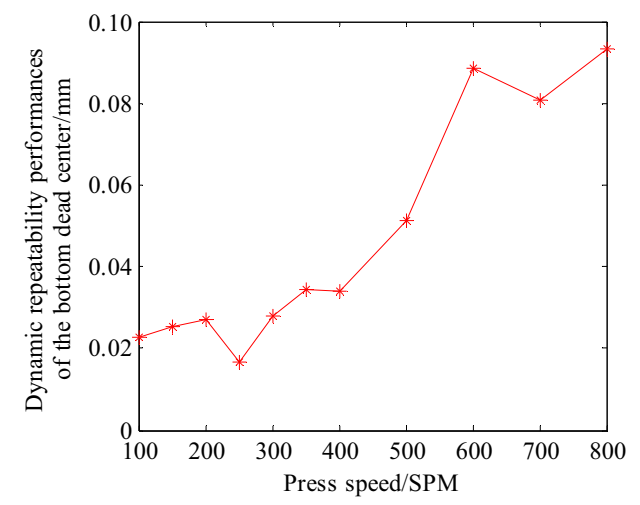

Figure 2. The change curve of bottom dead center precision.

\subsection{Accelerated accelerating stress}

Accelerated stress should be able to stimulate failure or accelerate performance degradation of parts, and cannot change the failure mechanisms in normal use. Increasing the punch load and press speed of the punch can check the reliability of the transmission system consists of motor, flywheel, clutch, crankshaft, connecting rod, and the slide block and other components. As the working load and speed increased, the friction torque of the crankshaft gets larger and brings out a large amount of heat, which will result in thermal deformation and transmission precision reduction. In addition, as the punch load and press speed increased, the inertial load and the vibration stress are also increased. This will stimulate failure or accelerate performance degradation of parts, such as mechanical fatigue, mechanical wear and fracture.

Through the failure analysis of high-speed punch, the punch load and press speed can be selected as accelerated stresses. Considering the fact that the punch load is harder to control, press speed is finally selected as accelerated stress.

\subsection{Reliability accelerated test}

All the technical parameters of operation need to be monitored in reliability test. According to the failure mechanism analysis of the high-speed punch, the test content is made as shown in Fig. 3, based on which the performance degradation and failure condition during operation can be analyzed. The test object, which is customized and fewer in number, is high in cost. Comprehensive considering all the circumstances, the number of test object is preliminarily determined to be $1 \sim 3$, but the specific number is determined by the actual circumstances. The test is on the premise of not destroying high-speed punch with censored time as its termination conditions.

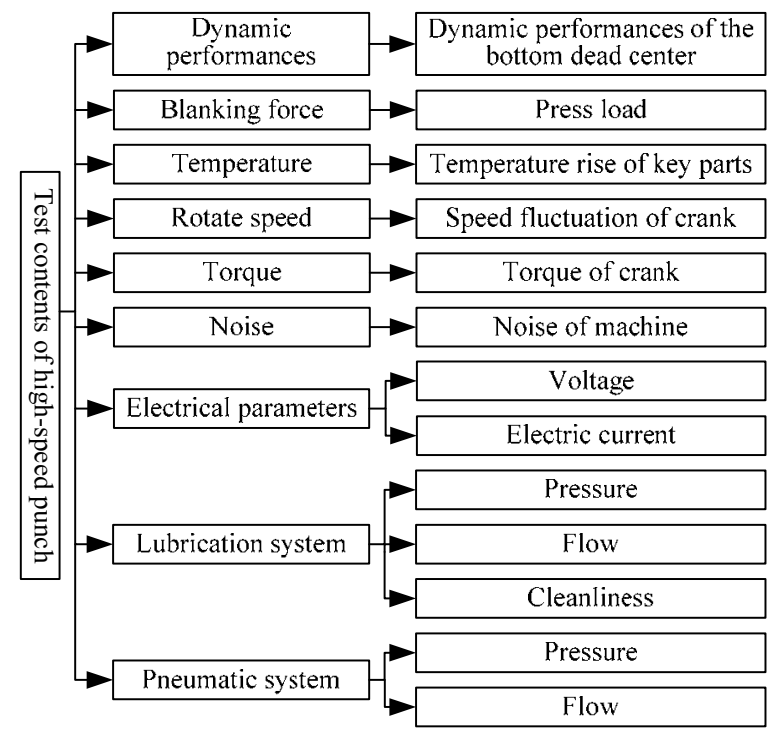

Figure 3. The test content of high-speed punch.

\section{Preliminary test verification}

A dynamic accuracy test of slider block was carried out on a certain high-speed punch whose nominal force is $800 \mathrm{KN}$. Three displacement sensors are located at a block fixed on the workbench to measure the dynamic accuracy of the slider block along X-, Y- and Z-direction, respectively, see in Fig. 4.

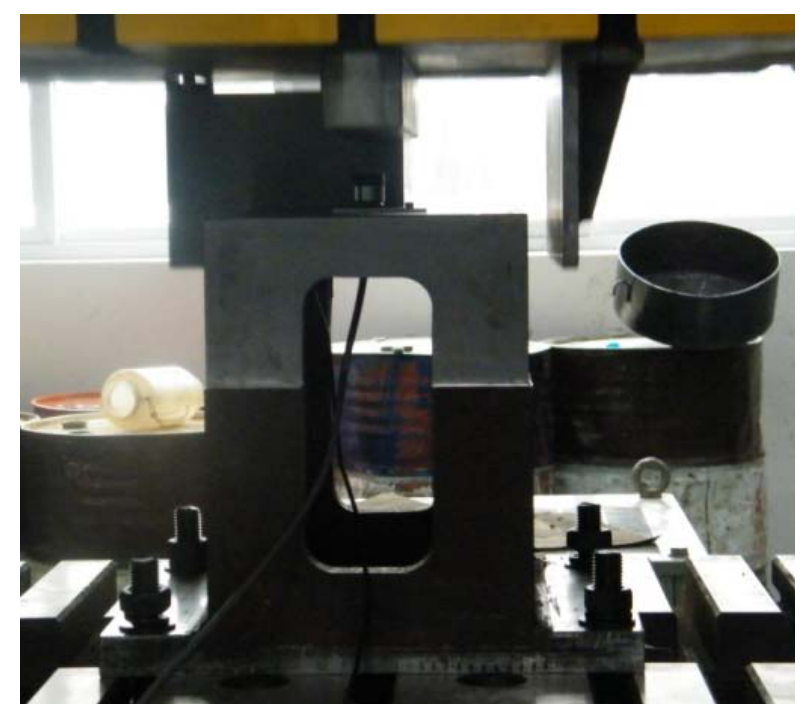

Figure 4. Dynamic precision test of slide block.

Measurement scheme is as follows: In idle load cases, the dynamic accuracies of the slider block along three directions were measured simultaneously with the punching speed increasing from 100SPM to 800SPM gradually. After each speed-up, the signals were acquired while the speed was stabilized. The averaged positions and averaged repetitive positioning accuracies calculated from the testing results are shown in Fig. 5. 

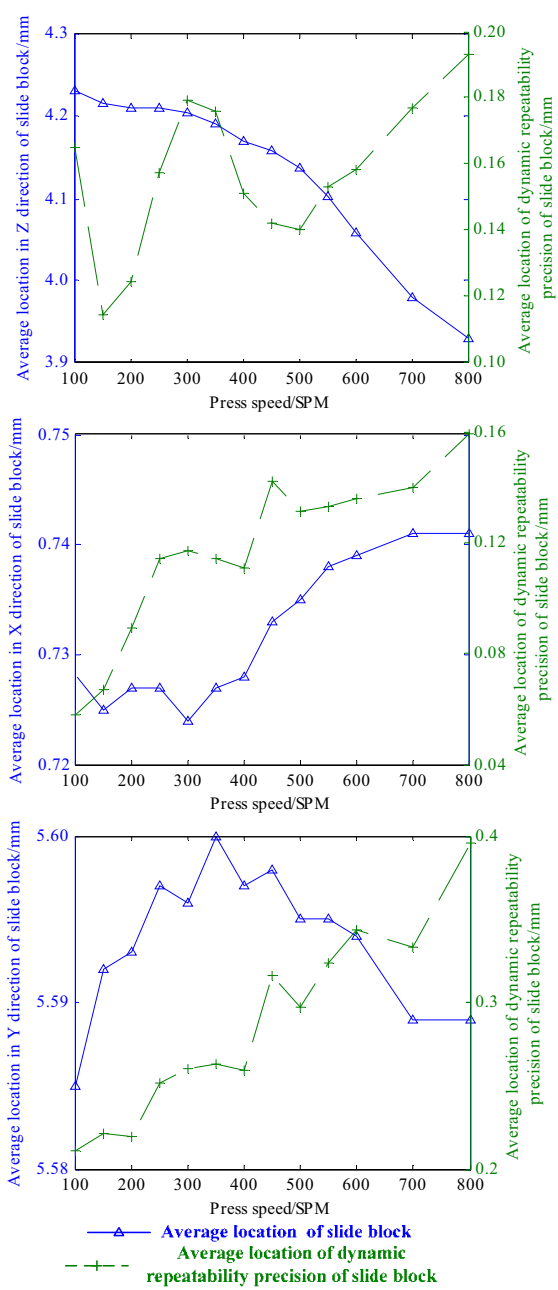

Figure 5. Dynamic precision of slide block.

From the Fig. 5 one can see that, as the punching speed increasing, the averaged position of the BDC of slide block falls down subsequently, and the mean value of $\mathrm{X}$ direction position of slide block gets bigger, this error is the primitive error, which is in proportion to punch speed. Simultaneously, the mean value of Y direction of slide block first increases and then decreases, the difference value between the maximum and minimum value is $0.015 \mathrm{~mm}$ which is not very big, and there is no regularity. Therefore, slide block Y direction position mean is approximate seen the same in the speed change process. From the overall trend analysis, the dynamic repetitive positioning accuracy of slide block increases with the intensity of punch speed. With the increase of punch speed, the vibration and thermal deformation of the punch increase, therefore the slide block dynamic accuracy is declined.

According to the survey data analysis, the dynamic accuracy of slide block: Dynamic accuracy of $X$ direction is higher, dynamic accuracy of $\mathrm{Z}$ direction takes second place, and dynamic accuracy of $Y$ direction is worst. The test results provide some important information for the reliability growth of the high-speed punch.

\section{Summary}

The failure analysis of high-speed punch was analyzed based on the failure and maintenance data and the weakest links of the high-speed punch were pointed out. The reliability accelerated test system of high-speed punch was built after the analysis of failure measurability and failure mechanisms. The pretest, which is demonstrated reasonable and effectively by the analysis of the reason of the dynamic repeatability precision decline of the bottom dead center, laid the foundation for the comprehensive test of the high-speed punch.

\section{Acknowledgments}

This work was financially supported by Fundamental Research Project of the Natural Science in Colleges of Jiangsu Province of China (Grant No. 15KJB460005), Jiangsu Planned Projects for Postdoctoral Research Funds (Grant No. 1501102C), Advanced Talent Foundation of Jiangsu University of China (Grant No. 14JDG138).

\section{References}

1. D.Aimin, C. Xun, Z. Chunhua, W. Yashun. Acta Armamentarii 28, 8 (2007)

2. C. Xun, Z. Chunhua. Journal of Mechanical Engineering 45, 8 (2009)

3. W. B. Nelson. IEEE Transactions on Reliability 30, 2 (1981)

4. V. R. B. Oliveira, E. A. Colosimo. Quality and Reliability Engineering International 20 (2004)

5. R. B. Chinnam. Quality and Reliability Engineering International 18 (2002)

6. W. Yiqiang, J. Yazhou, J. Weiwei. Reliability Engineering \& System Safety 72, 1 (2001)

7. Z. Yingzhi, J. Yazhou, Z. Xuewen, D. Qinglin. Journal of Jilin University (Engineering and Technology Edition) 34, 2 (2004)

8. A. Adamyan, H. David. Reliability Engineering \& System Safety 76, 3 (2002)

9. S. T. Tseng, N. Balakrishnan, C. C. Tsai. IEEE Transactions on Reliability 58, 4 (2009)

10. W. Shipeng, X. Yancai. International Journal of Advancements in Computing Technology 3, 8 (2011)

11. Z. Genbao, X. Zhi, H. Wenhui, T. Lin. China Mechanical Engineering 22, 8 (2011)

12. H. Ye. Changchun: Jilin University (2008)

13. S. Hiroshi. Reliability engineering(Beijing: Science Press, 1982) 